\title{
Aspirin-induced asthma: a tribute to John Vane as a source of inspiration
}

\author{
Andrzej Szczeklik \\ Department of Medicine, Jagiellonian University Medical College, Skawińska 8, PL 31-066 Kraków, Poland \\ Correspondence: Andrzej Szczeklik, e-mail: mmszczek@cyf-kr.edu.pl
}

\begin{abstract}
:
Aspirin-induced asthma is a distinct clinical syndrome consisting of inflammation, characterized by chronic eosinophilic rhinosinusitis with asthma and often nasal polyposis. Aspirin and other nonsteroidal anti-inflammatory drugs (NSAIDs) exacerbate asthma, resulting in violent attacks. This is the hallmark of the clinical syndrome as explained by the cyclooxygenase theory. This theory, which is now generally accepted, states that asthma attacks precipitated by aspirin and other NSAIDs have no allergic background; instead, they occur due to the inhibition of cyclooxygenase-1 in sensitive patients. This paper describes how the discoveries of John Vane inspired the authors of the cyclooxygenase theory and led to further insight into the biology of eicosanoid metabolism in this relatively common type of asthma.
\end{abstract}

Key words:

aspirin, asthma, cyclooxygenase, prostanoids, leukotrienes

\section{Introduction and historical note}

When we search for the origins of concepts, notions and ideas, we turn to the ancient Greeks. However, where did the Greeks get their sources? In Homer. The Greeks never looked further back than Homer because they did not believe it was necessary. Interestingly, it is in the Iliad that we first encounter the onomatopeic word $\alpha \sigma \theta \mu \alpha$. Homer used it to describe Hector, who, after being chased by Achilles three times around the walls of Troy, lied prostrated in terrible breathlessness ("astmati”).

Asthma has been familiar to man throughout history. Its clinical features are well known, and various forms of asthma have been described. However, a new type of asthma appeared at the beginning of the
XXth century, and its appearance coincided with the introduction of aspirin as a therapy [5]. Reports of anaphylactic-like reactions to aspirin soon became public. The major type of adverse reaction was acute bronchospasm. These symptoms began 15 to $20 \mathrm{~min}$ after the ingestion of aspirin, sometimes resulting in fatal asphyxiation. The association of aspirin hypersensitivity, asthma and nasal polyps was first recorded by Widal in 1922. Over the years, it became evident that aspirin-induced asthma (AIA) is a distinct clinical syndrome of intractable inflammation in both the upper and lower respiratory tracts and is characterized often by chronic rhinosinusitis and nasal polyposis. Because exposure to aspirin does not initiate the underlying inflammatory process, AIA is increasingly referred to as aspirin-exacerbated respiratory disease (AERD). 


\section{Prevalence, natural history and clinical presentation}

AIA remains largely underdiagnosed. Many patients may not be aware of aspirin hypersensitivity because they deliberately avoid nonsteroidal anti-inflammatory drugs (NSAIDs) due to their well-known adverse effects. Alternatively, they may experience mild asthma attacks after ingesting NSAIDs but do not correlate the two events. A main factor in underdiagnosing aspirin hypersensitivity is the lack of diagnostic aspirin challenges, simply because many physicians are afraid of them. In one European survey, $15 \%$ of asthmatic subjects were unaware of their aspirin sensitivity before undergoing positive aspirin provocation tests. In a meta-analysis of 15 studies that used oral aspirin challenges to detect AIA in adult asthmatics, the average prevalence was $21 \%$ [4]. In patients with rhinosinusitis and nasal polyposis, the prevalence of aspirin hypersensitivity is even higher, reaching $30-40 \%$.

Females are predominant in this aspirin-sensitive population for unknown reasons. They outnumber men by a ratio of 2.5 to 1 . In general, the disease develops according to a characteristic pattern with a distinct sequence of symptoms. While patient history may be suggestive of the syndrome, the definitive diagnosis is made only with challenge (provocation) tests.

AIA is usually proceeded by chronic rhinitis/rhinosinusitis. According to two large studies involving patients from Europe [8] and the United States [1], the first nasal symptoms appeared at the age of 29 and 34 years, respectively. The presentation starts as watery rhinitis and nasal congestion, and many patients describe an upper respiratory tract infection (common cold). Perhaps a viral infection may initiate the vicious circle of inflammatory events leading to AIA in genetically susceptible subjects [6]. Asthma is diagnosed usually $2-3$ years later, and adverse clinical reactions precipitated by aspirin or other NSAIDs appear in patients who previously tolerated these drugs very well. The "classic" adverse reactions to aspirin ingestion include bronchospasm of variable severity, usually accompanied by profuse rhinorrhea and nasal congestion. Additionally, sneezing, itching, ocular "injection" tearing and, to a lesser extent, periorbital swelling can occur. Some patients experience skin rush and erythema of the head and neck. The severity of adverse reactions to aspirin or other NSAIDs may range from isolated rhinitis to life-threatening anaphylactic reactions. In some patients, aspirin ingestion may lead to nausea, stomach cramps, or myocardial ischemia [9].

AIA is a severe type of asthma and runs a protracted course even after complete avoidance of aspirin and other NSAIDs. Up to $50 \%$ of patients require systemic corticosteroids to control their asthma. In a recent Japanese study, patients with multiple exacerbations of asthma more frequently had hypersensitivity to aspirin and reported more asthma-related hospitalizations. Aspirin hypersensitivity was also strongly associated with near-fatal asthma [10].

Positive skin-prick tests to at least one aeroallergen were documented in $34-64 \%$ of patients with AIA. Marked blood and sputum eosinophilia are common. The majority of patients suffer from chronic hypereosinophilic sinusitis and polyposis that usually fills all of the sinuses and destroys bone structures. The development of nasal polyposis is indicated by the loss of smell, and normal olfaction correlates negatively with AIA diagnosis. Symptoms from the upper respiratory tract are often exacerbated by sinus infections, which on average occur five to six times per year. Aspirin-sensitive nasal polyps are characterized by rapid regrowth, resulting in multiple sinus surgeries. The involvement of the sinuses, as evidenced by computed tomography, occurs with a higher magnitude in AIA patients compared to patients who tolerate aspirin well.

\section{Mechanisms of the disease}

Sudden and dangerous reactions to aspirin have raised substantial interest in the topic. Several theories regarding the origin of these reactions have been proposed, but these remain unsubstantiated and lack scientific evidence. In the early seventies, an allergy was widely believed to underlie these reactions. However, both skin tests with aspirin and a search for antiaspirin antibodies in the blood of the patients were negative. At about this time, I noticed that other NSAIDs in addition to aspirin could precipitate similar reactions. We discussed these observations with Richard Gryglewski and set up a study that was inspired by the recent discovery of John Vane [12], who 
demonstrated that aspirin and several other NSAIDs act by inhibiting one enzyme, cyclooxygenase (COX) [2]. Could this be the case with our patients? At the clinical site, we collected about 40 AIA patients and started to challenge them carefully with increasing doses of 20 different NSAIDs. The challenges began with very small doses; they were closely monitored by a physician and coupled with lung function tests. We found that some NSAIDs caused bronchial obstruction, while others were well tolerated. In the Department of Pharmacology, Richard Gryglewski and his team checked the ability of the same compounds to inhibit cyclooxygenase in vitro. They used the bioassay technique developed by John Vane. When we combined the results of the in vivo and vitro studies, we found that compounds that precipitated bronchial obstruction in patients also inhibited COX in vitro, while those that were well tolerated lacked this activity. Moreover, there was a clear correlation between the potency of a drug to inhibit COX in vitro and its ability to precipitate a clinical reaction. We presented these results at an international conference in London in 1974 and published them in British Medical Journal in 1975 [7], expanding the results to other NSAIDs in the following two years. These results were confirmed by several other laboratories and led to the development of the cyclooxygenase theory of AIA. This theory states that asthma attacks precipitated by aspirin and several other NSAIDs are not due to allergies, but rather, they are due to the inhibition of COX-1 in the respiratory tract of the sensitive patients. The theory predicts drugs that can be taken safely by a patient and those that must be avoided. Furthermore, this theory indicated serious alterations in the metabolism of arachidonic acid in this type of asthma. In the following years, this led to the discoveries of other eicosanoid alterations that accompany AIA, such as overproduction of cysteinyl-leukotrienes or a deficiency of lipoxins. Perhaps a persistent, latent rhinovirus infection of the respiratory tract may be the origin of these alterations in arachidonate metabolism $[6,13]$. These concepts have been recently reviewed $[10,11]$.

It was John Vane's discovery of the action of aspirin that inspired Richard Gryglewski and I to carry out the studies briefly presented in this review. We were both very much influenced in our research by Sir John. Richard, of course, was John's closest collaborator and contributed greatly to several important discoveries [3]. I was privileged to know Sir John for over thirty years and was fortunate to share his friend- ship, creativity, inventiveness and brilliance. He was always ready to generate new ideas, to listen carefully to others and to ignite interest. Discussions regarding the current research took place every day in the laboratory and at the lovely parties hosted by Lady Daphne, Teresa Gryglewska and my wife Maria. Sir John was our guiding light. He attracted talented men and women from all over the world, with Richard Gryglewski being the best example. John, our mentor, opened new vistas in medicine and introduced us to the delights of science.

\section{Acknowledgment:}

This work was supported by a grant from the Foundation for the Advancement of Polish Pharmacy and Medicine

\section{References:}

1. Berges-Gimeno M, Simon RA, Stevenson DD: The natural history and clinical characteristics of aspirin exacerbated respiratory disease. Ann Allergy Asthma Immunol, 2002, 89, 474-478.

2. Bujalska M, Makulska-Nowak H: Bradykinin receptor antagonists and cyclooxygenase inhibitors in vincristineand streptozotocin-induced hyperalgesia. Pharmacol Rep, 2009, 61, 631-640.

3. Gryglewski RJ: Prostacyclin among prostanoids. Pharmacol Rep, 2008, 60, 3-11.

4. Jenkins C, Costello J, Hodge L: Systematic review of prevalence of aspirin-induced asthma and its implications for clinical practice. BMJ, 2004, 328, 434-437.

5. Settipane GA: Landmark commentary: history of aspirin intolerance. Allergy Proc, 1990, 11, 251-252.

6. Szczeklik A: Aspirin-induced asthma as a viral disease. Clin. Allergy, 1988, 18, 15-20.

7. Szczeklik A, Gryglewski RJ, Czerniawska-Mysik G: Relationship of inhibition of prostaglandin biosynthesis by analgesics to asthma attacks in aspirin-sensitive patients. Br Med J, 1975, 1, 67-69.

8. Szczeklik A, Nizankowska E, Duplaga M: Natural history of aspirin-induced asthma. AIANE Investigators. European Network on Aspirin-Induced Asthma. Eur Respir J, 2000, 16, 432-436.

9. Szczeklik A, Nizankowska E, Mastalerz L, Bochenek G: Myocardial ischemia possibly mediated by cysteinyl leukotrienes. J Allergy Clin Immunol, 2002, 109, 572-573.

10. Szczeklik A, Nizankowska-Mogilnicka E, Sanak M: Hypersensitivity to Aspirin and Nonsteroidal AntiInflammatory Drugs. In: Middleton's Allergy, 7th edn., Eds. Adkinson NF, Busse WW, Bochner BS, Holgate ST, Simons FGR, Lemanske RF, Mosby Elsevier, Philadelphia, PA, 2009, 1227-1243.

11. Szczeklik A, Niżankowska-Mogilnicka E, Sanak M: Hypersensitivity to aspirin and other NSAIDs. In: Allergy 
and Allergic Diseases. 2nd edn., Eds. Kay AB, Kaplan AP, Bousquet J, Holt PG, Wiley-Blackwell, New York, 2008, 1966-1979.

12. Vane JR: Inhibition of prostaglandin synthesis as a mechanism of action for aspirin-like drugs. Nature, 1971, 231, 232-234.

13. Wos M, Sanak M, Soja J, Olechnowicz H, Busse WW, Szczeklik A: Persistence of rhinovirus infection in lower airways of patients with bronchial asthma. Am J Respir Crit Care Med, 2008, 177, 1082-1089.

\section{Received:}

September 15, 2009; in revised form: April 26, 2010. 